\title{
Influence of accounting for thermodynamic processes on the processes of mixture formation during sequential pumping of petroleum products
}

\author{
Ivan M. Vanchugov* and Roman A. Shestakov* \\ National University of Oil and Gas « Gubkin University, 65 Leninsky Prospekt, Moscow 119991, Russia
}

Received: 9 November 2020 / Accepted: 15 December 2020

\begin{abstract}
In this paper, we study the processes of mixing when using the technology of transportation of light oil products-sequential pumping by direct contact. Modeling of mixing processes is carried out taking into account the influence of parametric and thermodynamic factors. For numerical modeling, a software package was developed that allows not only modeling and calculating the parameters of the oil pipeline operation in real time with subsequent graphical visualization, but also comparing them with real data processed by operators at production facilities.
\end{abstract}

\section{Introduction}

Currently, one of the most cost-effective and efficient types of transportation of petroleum products is pipeline transport [1-3]. The main oil pipelines that are already in operation are being transferred to the transportation of oil products [4]. However, despite its many advantages, it also has disadvantages, especially with regard to the sequential pumping of various grades of petroleum products through one pipeline, namely, the formation of a mixture of neighboring grades of petroleum products during sequential pumping [5-13]. In modern practice, the calculation methods and algorithms used in the design and operation of pipelines through which oil and petroleum products are pumped are based on the works of major pipeline transport scientists V.G. Shukhov, L.S. Leibenzon, M.V. Lurie, and others, as well as on works published in relatively recent times $[5,14-20]$. Research is also being carried out to reduce the volume of a mixture of different-grade oil products that occurs during sequential pumping [21], expand the range of oil products pumped by direct contact [6,22], and improve the accuracy of monitoring the boundaries of the mixing zone using instrument methods [23]. Also, the issue of managing, determining the volume of shipments and their distribution during pipeline transportation has been widely studied in the framework of multi-criteria management and logistics tasks [24-30].

This fact demonstrates that the subject is relevant, but even more important is research into the influence of

\footnotetext{
* Corresponding authors: imvanchugov@yandex.ru, shestakov.r@gubkin.ru
}

non-isothermal transfer in the processes of mixture formation and the parameters of the pumping mode for pipelines, working on a method of direct contact, but the pumping oil temperature effect is studied very well [5, 14-17, 31-33].

Thus, to assess the influence of temperature accounting, it is necessary to build a mathematical model of pipeline transportation of petroleum products by direct contact on the section of the main oil product pipeline between pumping stations. To do this, it is necessary to take into account not only the parameters of oil products, the pipeline and the pumping mode [34], but also the temperature distribution over the oil product pipeline section and the initial temperature of the pumped products. This is due to the fact that the hydraulic calculation is influenced by the parameters and results of thermal calculation, so this work eliminates simplifications and errors that are not taken into account in the isothermal calculation of the operation of the oil product pipeline and the processes of mixing as a result of its operation.

\section{Mathematical model and algorithm}

The primary task in modeling non-isothermal pumping is to simulate the movement of each oil product throughout the entire section of the oil product pipeline separately (assuming that this oil product completely fills the pipeline), to conduct intermediate calculations and obtain data that will be used in hydraulic calculation and in calculating the volume of the mixture.

The main essence of the mathematical model of nonisothermal sequential pumping of oil and petroleum 
products by direct contact method is that this model consists of several simpler models, as well as refinement by taking into account additional pumping parameters. The connection of petroleum products into a single mathematical model is carried out when modeling the operation of the entire pipeline.

Let's assume that $n \in \mathbb{N}$ oil products are pumped through a section of the main oil product pipeline, and $n \geq 2$, and the entire section of the oil product pipeline is filled with transported oil products at the initial time.

The simulation is performed in several iterations. First of all, the flow of each oil product is modeled separately, assuming that the entire oil product pipeline is filled with $j-m$ oil products, $j=1 \ldots n$, during which the thermodynamic parameters of pumping are determined - the heat transfer coefficient from the flow to the external environment, the primary temperature distribution along the axis of the oil product pipeline, as well as the parameters of the $j$ th oil product. During the next iteration, a more accurate distribution of the temperature of the $j$ th oil product along the axis of the oil product pipeline will be determined using the refined thermodynamic parameters of pumping.

To determine the state of the entire system, it is necessary to place batches of products in the oil product pipeline, assuming that at the initial time the first pumped product has reached the end of the linear section, and taking into account the mass of each oil product, as well as its density, obtained by refined thermodynamic calculation. The contact boundaries of petroleum products will be the middle of the mixture formed by them during sequential pumping.

Based on the main parameters obtained during the refined thermodynamic calculation, the volume of the mixture, its boundaries with each of the oil products, as well as the distribution of concentrations, density and viscosity of the mixture are determined. Thus, simple mathematical models of non-isothermal pumping of each oil product are combined into a single complex model, but this is not all.

To achieve a better connection between the model and industry, the final model was integrated with a model of operation of main and back-up pumps with the possibility of implementing various connection schemes and operating modes.

In order to perform hydraulic and thermodynamic calculations based on the presented model, it is necessary to know the parameters of the pipeline, the transported products, and the temperature distribution of the environment surrounding the oil product pipeline.

1. Parameters of the linear part of the pipeline:

- $x$ - coordinate, $\mathrm{m}$;

- $z(x)$ - height, m;

- $D$ - outer diameter, mm;

- $\delta$ - wall thickness, mm;

- $d=(D-2 \cdot \delta) / 1000$ - outer diameter, m;

- $\Delta$ - the absolute roughness of the wall, mm;

- $T_{\text {surr. area }}(x)$ - the temperature of the surrounding area (soil), K;

- $\lambda_{\text {wl.pl. }}(x)-$ coefficient of thermal conductivity of the pipeline wall material, $\mathrm{W} /(\mathrm{m} \mathrm{K})$;
- $\lambda_{\text {surr. area }}(x)$ - soil thermal conductivity coefficient, $\mathrm{W} /(\mathrm{m} \mathrm{K})$;

- $h_{0}(x)$ - the depth of the pipeline, $m$;

- $T_{\text {wl. pl. }}(x)$ - the wall temperature of the pipeline, $\mathrm{K}$.

2. Parameters of pumped oil products:

- $\rho_{0}$ - density of petroleum product under normal conditions, $\mathrm{kg} / \mathrm{m}^{3}$;

- $v_{0}$ - kinematic viscosity of petroleum products under normal conditions, cSt;

- $T_{\text {n.c. }}$ - temperature of normal conditions, $\mathrm{K}$;

- $m$ - weight of oil product, t;

- $C_{p_{0}}$ - initial specific heat of the oil product, $\mathrm{W} /(\mathrm{m} \mathrm{K})$;

- $\lambda_{0 \mathrm{OP}}-$ coefficient of thermal conductivity of petroleum product under normal conditions, $\mathrm{W} /(\mathrm{m} \mathrm{K})$;

- $\alpha_{0}$ - average temperature correction of density when the oil product temperature changes by $1 \mathrm{~K}$;

- $u_{0}$ - coefficient of steepness of the viscogram;

- $T_{0}$ - initial temperature of the oil product, $\mathrm{K}$.

The calculation algorithm is described below, during which the main technological parameters are determined using the proposed mathematical model, taking into account the above clarifications.

First of all, the external heat transfer coefficient from the pipe wall to the environment is determined by the formula (1):

$$
\alpha_{2}(x)=\frac{2 \times \lambda_{\text {surr. area }}(x)}{D \times \ln \left(2 \times \frac{h_{0}(x)}{D}+\sqrt{\left(\frac{h_{0}(x)}{D}\right)^{2}-1}\right)}, \frac{W}{\mathrm{~m}^{2} \mathrm{~K}} .
$$

After that, the distribution of parameters of each transported oil product along the pipeline length is calculated. The Isobaric heat capacity is determined in accordance with (2), the density is (3), and the kinematic viscosity coefficient is (4):

$$
\begin{aligned}
c_{p_{\text {wl. }}}(x)_{j}= & 1.5072+\frac{T_{\text {wl.pl. }}(x)_{j}-223}{100} \\
& \times\left(1.7182-1.5072 \times \rho_{0 j}\right), \frac{\mathrm{J}}{k g \mathrm{~K}},
\end{aligned}
$$

where

$j$ - oil product number in the batch,

$T_{\text {wl.pl. }}(x)_{\mathrm{j}}$ - temperature of the pipeline wall, in crosssection with $x$ coordinate, if $x=0$, then $T(x)_{j}=T_{0 j}$.

$$
\begin{gathered}
\rho_{\text {wl.pl. }}(x)_{j}=\rho_{0 j}+\alpha_{0 j} \cdot\left(T_{\text {n.c. }}-T_{\text {wl.pl. }}(x)_{j}\right), \frac{\mathrm{kg}}{\mathrm{m}^{3}} . \\
v_{\text {wl.pl. }}(x)_{j}=v_{0 j}^{*} \cdot e^{-u_{0 j} \cdot\left(T_{\text {wl.pl }}(x)_{j}-T_{\text {n.c. }}\right)}, \mathrm{cSt} .
\end{gathered}
$$

Since the physical parameters of the transported products are not constant and change along the length of the pipeline, and the ambient temperature can change along the length of the route, the parameters of the process of TV transmission from the transported products to the 
environment will be represented as functions for each transported product in the form of a distribution along the length of the pipeline. The main thermal parameter of the pipeline is the transfer coefficient, which is determined according to (9), but its distribution along the length of the pipeline for each product to calculate the distribution coefficient of heat conductivity of oil according to (5), Prandtl number (6), as the velocity of the oil - (7), the internal heat transfer coefficient from the fluid to the wall of the pipe (8):

$$
\begin{aligned}
& \lambda_{\mathrm{OP} \text { wl. }}(x)_{j}=\lambda_{0 \mathrm{OPj}} \cdot\left(1-\alpha_{0 j} \cdot\left(T_{\text {n.c. }}-T_{\text {wl.pl. }}(x)_{j}\right)\right), \frac{\mathrm{W}}{m \mathrm{~K}} . \\
& \operatorname{Pr}_{\mathrm{wl} .}(x)_{j}=\frac{c_{p_{\mathrm{wl} .}}(x)_{j} \cdot \rho_{\mathrm{wl} .}(x)_{j} \cdot v_{\mathrm{wl} .}(x)_{j}}{\lambda_{\mathrm{OP} \mathrm{wl} .}(x)_{j}} \\
& v(x)_{j}=\frac{4 \cdot Q}{\pi \cdot d^{2}}, \frac{\mathrm{m}}{\mathrm{s}} . \\
& \alpha_{1}(x)_{j}=0.021 \times \varepsilon_{k}(x) \times\left(\frac{1}{\operatorname{Pr}_{\mathrm{wl} .}(x)_{j}}\right)^{0.25} \times \frac{\left(v(x)_{j} \cdot d\right)^{0.8}}{v(x)_{j}^{0,12}} \\
& \times\left(\frac{c_{p}(x)_{j} \times \rho(x)_{j}}{\lambda_{O P}(x)_{j}}\right)^{0.68}, \frac{\mathrm{W}}{\mathrm{m}^{2} \cdot \mathrm{K}} .
\end{aligned}
$$

where $\epsilon_{k}(\mathrm{x})$ is correction factor that depends on the ratio of the length of the pipe section to its internal diameter in turbulent conditions $\epsilon_{k}(\mathrm{x})=1$ :

$$
k(x)_{j}=\frac{1}{\frac{1}{\alpha_{1}(x)_{j} \cdot d}+\frac{1}{\alpha_{2}(x)_{j} \cdot d}+\frac{\ln \left(\frac{D}{d}\right)}{2 \cdot \lambda_{\mathrm{wl} . \mathrm{pl}}}} .
$$

Next, the temperature distribution of the pumped product along the length of the pipeline is determined, taking into account heat exchange with the environment and energy dissipation to overcome friction forces with the release of heat. To do this, it is necessary to perform a calculation algorithm according to formulas (10)-(15) with a step $\Delta x$. This algorithm is described in [5, 14], but it is used to determine the average pipeline parameters of oil, which is not suitable for carrying out refined calculations of sequential pumping of petroleum products.

Shukhov coefficient of petroleum products:

$$
\operatorname{Shu}(x)_{j}=\frac{\pi \times k(x)_{j} \times d \times x}{Q \times \rho_{0}(x)_{j} \times c_{p}(x)_{j}} .
$$

Reynolds number of petroleum product:

$$
\operatorname{Re}(x)_{j}=\frac{v(x)_{j} \times d}{v(x)_{j}} .
$$

The coefficient of relative roughness of pipes:

$$
\varepsilon=\frac{\Delta}{D-2 \cdot \delta} .
$$

The coefficient of hydraulic resistance, in a section with a coordinate $x$ according to $[5,15]$. Hydraulic slope ratio:

$$
i(x)_{j}=\lambda(x)_{j} \times \frac{1}{d} \times \frac{v(x)_{j}{ }^{2}}{2 \cdot g},
$$

where $g=9.80665 \mathrm{~m} / \mathrm{c}^{2}-$ acceleration of free fall.

Coefficient $b$ for determining the influence of viscous friction forces in the cross section with the coordinate:

$$
b(x)_{j}=\frac{v(x)_{j} \cdot d \cdot g \cdot i(x)_{j}}{k(x)_{j} \cdot 4} .
$$

The temperature distribution of an oil product is a set of temperature values:

$$
\begin{gathered}
T(x)_{j}=T_{\text {surr. area }}(x)+\left(T_{0 j}-T_{\text {surr. area. }}(x)\right) \cdot e^{-\operatorname{Shu}(x)_{j}} \\
+b(x)_{j} \cdot\left(1-e^{-\operatorname{Shu}(x)_{j}}\right) .
\end{gathered}
$$

Next step of calculation:

$$
x=x+\Delta x .
$$

Calculations are performed for each of the points with coordinates $x \in[0 ; L]$ and step $\Delta x=L / 1000$, where $L$ - is length of the oil product pipeline section.

After the determination of temperature distribution of products along the length of the plot is the updated recalculation of the distribution of values of the physical properties of products (2)-(4). That allows to increase the accuracy of determining the volume of each batch of petroleum product during its movement through the pipeline, the accuracy of calculating the parameters of the transportation mode of petroleum products and the volume of the mixture of the neighboring oil, which is determined by $(17)[5,17]$ :

$$
V_{c j}=1000 \times\left(\lambda_{j}^{1.8}-\lambda_{j-1}^{1.8}\right) \times\left(\frac{d}{L}\right)^{0.43} \cdot V_{j},
$$

where $V_{j}=\frac{\mathrm{L}}{4} \cdot \pi \cdot d^{2}-$ is internal volume of the part of the pipeline passed by the party.

So, after constructing a mathematical model, it is necessary to numerically evaluate the effect of changes in the temperature of petroleum products along the length of the pipeline on the volume of the resulting mixture and the parameters of the pumping mode.

\section{Results and discussion}

As an example, let's consider three variants of a pipeline with a variety $\emptyset 630 \times 7 \mathrm{~mm}, \emptyset 530 \times 7 \mathrm{~mm}$ and $\emptyset 426 \times$ $7 \mathrm{~mm}$, the other parameters are assumed to be the same for all three varieties: $\Delta=0.01 \mathrm{~mm}, \lambda_{\text {wl.pl. }}=44 \mathrm{~W} /(\mathrm{m} \mathrm{K})$, $\lambda_{\text {soil }}=1.05 \mathrm{~W} /(\mathrm{m} \mathrm{K}), T_{\text {wl.pl. }}$ (summer) $=288.15 \mathrm{~K}, T_{\text {wl.pl. }}$ (winter) $=263.15 K$. The route profile is shown in Table 1 , the ambient temperature distribution along the pipeline route is shown in Table 2, the parameters of transported products are shown in Table 3 .

For numerical simulation, a software package was developed in accordance with the mathematical algorithm 
Table 1. Profile of the linear part of the pipeline.

\begin{tabular}{|c|c|c|c|c|c|c|c|c|c|c|c|}
\hline$x(\mathrm{~km})$ & 0 & 10 & 20 & 30 & 40 & 50 & 60 & 70 & 80 & 90 & 100 \\
\hline$z(\mathrm{~m})$ & 100 & 110 & 120 & 130 & 140 & 150 & 140 & 130 & 120 & 110 & 100 \\
\hline
\end{tabular}

Table 2. Ambient temperature along the pipeline route at different times of the year.

\begin{tabular}{ccc}
\hline & $T_{\text {surr.area }}(\mathrm{K})$ & \\
\hline Summer (South-North/North-South) & Winter (South-North/North-South) & Isothermal (Summer/Winter) \\
\hline $302.650 / 298.750$ & $252.650 / 247.650$ & $288.15 / 253.15$ \\
$302.150 / 299.150$ & $252.650 / 248.150$ & $288.15 / 253.15$ \\
$301.650 / 299.550$ & $251.650 / 248.650$ & $288.15 / 253.15$ \\
$301.150 / 299.950$ & $251.150 / 249.150$ & $288.15 / 253.15$ \\
$300.650 / 300.350$ & $250.650 / 249.650$ & $288.15 / 253.15$ \\
$300.750 / 300.750$ & $250.150 / 250.150$ & $288.15 / 253.15$ \\
$300.350 / 300.650$ & $249.650 / 250.650$ & $288.15 / 253.15$ \\
$299.950 / 301.150$ & $249.150 / 251.150$ & $288.15 / 253.15$ \\
$299.550 / 301.650$ & $248.650 / 251.650$ & $288.15 / 253.15$ \\
$299.150 / 302.150$ & $248.150 / 252.150$ & $288.15 / 253.15$ \\
$298.750 / 302.650$ & $247.650 / 252.650$ & $288.15 / 253.15$ \\
\hline
\end{tabular}

Table 3. Parameters of the studied petroleum products [35, 36].

\begin{tabular}{lcccccccc}
\hline $\begin{array}{l}\text { Type of } \\
\text { oil product }\end{array}$ & $\rho, \frac{\mathrm{kg}}{\mathrm{m}^{3}}$ & $v, \mathrm{cSt}$ & $M$, tons & $C_{\mathrm{p}}, \frac{\mathrm{J}}{\mathrm{m} \cdot \mathrm{K}}$ & $\lambda_{0}, \frac{\mathrm{J}}{\mathrm{kg} \cdot \mathrm{K}}$ & $\alpha \times 10^{-6}$ & $u_{0} \times 10^{-5}$ & $\begin{array}{c}T_{0}, \mathrm{~K} \\
\text { (Summer } / \text { Winter/Isothermal } \\
\text { Summer/Winter) }\end{array}$ \\
\hline SDF & 840 & 2 & 5000 & 2010 & 0.11 & 7120 & 3677 & \\
WDF & 860 & 4 & 5000 & 2010 & 0.11 & 7120 & 6847 & $303.15 / 258.15$ \\
AI-80 & 715 & 0.62 & 3000 & 2090 & 0.11 & 8840 & 1178 & $288.15 / 258.15$ \\
AI-92 & 735 & 0.64 & 3000 & 2090 & 0.11 & 8570 & 1178 & 1178 \\
AI-95 & 750 & 0.68 & 3000 & 2090 & 0.11 & 8310 & \\
\hline
\end{tabular}

described above, which shows the numerical values of the pumping parameters in a cross-section (Figs. 2 and 3). The input data window is shown in Figure 1.

As the results of numerical modeling of sequential pumping of petroleum products, the volumes of a mixture of contacting petroleum products - automobile gasoline brands were determined AI-76, AI-80, AI-92 and AI-95, as well as the pressure and head drop required to ensure the specified flow rate.

To conduct a numerical study, a simulation was carried out taking into account different pumping conditions by time of year-summer and winter, which will allow us to clarify the volume of mixtures obtained during pumping, as well as the pressure and head losses for pumping in a given mode. As a result of various factors, it may be necessary to perform reverse pumping, so to study the direction of pumping within the framework of changing climatic parameters, numerical modeling of sequential pumping for selected pipeline grades from South to North and from North to South during the summer and winter periods of operation was carried out. However, in order to compare and determine the degree of influence of the inhomogeneity of the temperature distribution on the pipeline route, isothermal calculations were performed during the summer and winter periods of operation.

The numerical simulation results to pipeline export product mix $\emptyset 426 \times 7 \mathrm{~mm}$ with a volume flow of $1044 \mathrm{~m}^{3} / \mathrm{h}$ are presented in Table 4, a graphical rsepresentation of the dependence of the volume of the mixture from pump in Figure 4, and values of the required differential pressure and head - Figure 5.

Numerical results of simulation of pipeline pumping by assortment $\emptyset 530 \times 7 \mathrm{~mm}$ with the expense $1800 \mathrm{~m}^{3} / \mathrm{h}$, is shown in Table 5, a graphical representation of the dependence of the volume of the mixture on the pumping conditions is shown in Figure 6, and the values of the required pressure drop and head are shown in Figure 7.

Numerical results of modeling pumping through a pipeline with a range of $\emptyset 630 \times 7 \mathrm{~mm}$ with a flow rate of $2880 \mathrm{~m}^{3} / \mathrm{h}$ are shown in Table 6 , a graphical representation 


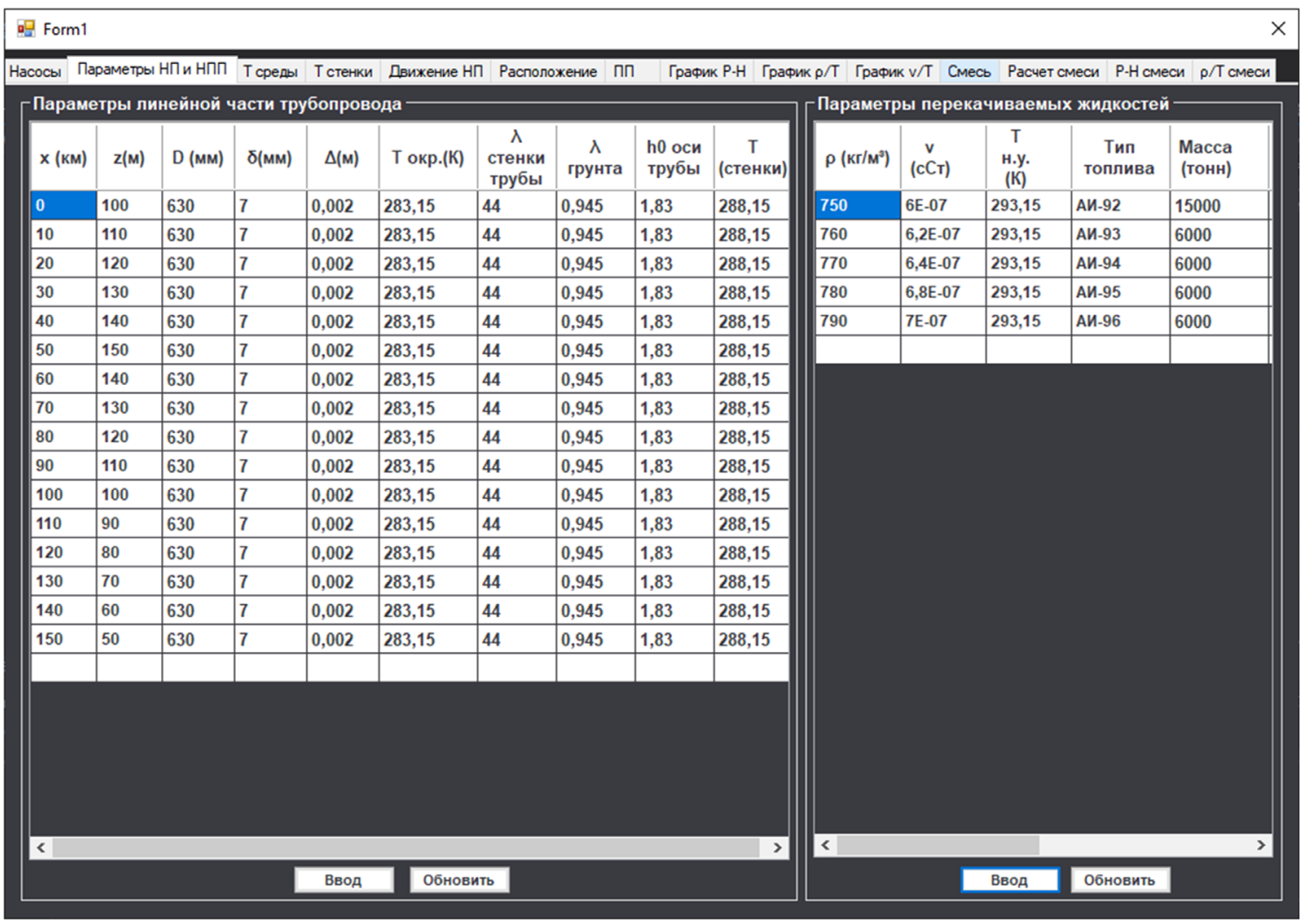

Fig. 1. Form for entering characteristics of pumped liquids and parameters of the linear part of the pipeline.

\begin{tabular}{|c|c|c|c|c|c|c|c|c|c|c|c|c|}
\hline \multicolumn{13}{|l|}{ 吗 Form1 } \\
\hline Насосы & Параметр & НПинПП & Тсреды & Т стенки Двих & иижение $\mathrm{H} \overline{\mathrm{Pa}}$ & Расположение ПП & График Р.H & H График $\rho / \tau$ & Т График $v / T$ & CMecb $P a$ & Расчет смеси Р.H смес & cn $\mathrm{p} / \mathrm{T}$ смеси \\
\hline $\mathrm{x}(\mathrm{kM})$ & $\begin{array}{c}\mathrm{D} \\
\text { (мм) }\end{array}$ & $\begin{array}{c}\sigma \\
\text { (мм) }\end{array}$ & $\begin{array}{l}\mathrm{T} \\
\text { okp } \\
\text { (K) }\end{array}$ & А грунта & $\begin{array}{c}\text { А стенки } \\
\text { трубы }\end{array}$ & \begin{tabular}{l|c} 
n & h0 оси \\
трубы (м)
\end{tabular} & $\begin{array}{l}\text { T стенки } \\
\text { (К) }\end{array}$ & $\begin{array}{c}\mathrm{a} 2 \\
\mathrm{BJ} /\left(\mathrm{M}^{\wedge} 2^{*} K\right)\end{array}$ & 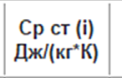 & $\begin{array}{l}\rho(i) c r \\
\left(\kappa r / M^{\wedge} 3\right)\end{array}$ & $v(\mathrm{i}) \mathrm{ct}(\mathrm{c} C \mathrm{C})$ & $\begin{array}{c}\lambda(\mathrm{i}) \mathrm{ct} \\
\mathrm{Br} /(\mathrm{M} \cdot \mathrm{K})\end{array}$ \\
\hline 0,00 & 630 & 7 & 283,15 & 0,945 & 44 & 1,83 & 288,15 & $1,39900722 \ldots$ & 1890,1517 & 750,004155 & $6,3640150111187 \ldots$ & $0,11045 \ldots$ \\
\hline 0,15 & 630 & 7 & 283,15 & 0,945 & 44 & 1,83 & 288,15 & 1,39900722 . & 1890,1517 & 750,004155 & $6,3640150111187 \ldots$ & 0,11045 \\
\hline 0,30 & 630 & 7 & 283,15 & 0,945 & 44 & 1,83 & 288,15 & $1,39900722 \ldots$ & 1890,1517 & 750,004155 & $6,3640150111187 \ldots$ & $0,11045 \ldots$ \\
\hline 0,45 & 630 & 7 & 283,15 & 0,945 & 44 & 1,83 & 288,15 & $1,39900722 \ldots$ & 1890,1517 & 750,004155 & $6,3640150111187 \ldots$ & $0,11045 \ldots$ \\
\hline 0,60 & 630 & 7 & 283,15 & 0,945 & 44 & 1,83 & 288,15 & $1,39900722 \ldots$ & 1890,1517 & 750,004155 & $6,3640150111187 \ldots$ & $0,11045$. \\
\hline 0,75 & 630 & 7 & 283,15 & 0,945 & 44 & 1,83 & 288,15 & $1,39900722 \ldots$ & \multirow{2}{*}{\multicolumn{2}{|c|}{\begin{tabular}{c|c}
1890,1517 & 750.904155 \\
1,39900722463228 \\
\end{tabular}}} & $6,3640150111187 \ldots$ & $0,11045 \ldots$ \\
\hline 0,90 & 630 & 7 & 283,15 & 0,945 & 44 & 1,83 & 288,15 & 1,39900722 & & & $6,3640150111187 \ldots$ & $0,11045$. \\
\hline 1,05 & 630 & 7 & 283,15 & 0,945 & 44 & 1,83 & 288,15 & $1,39900722 \ldots$ & 1890,1517 & 750,004155 & $6,3640150111187 \ldots$ & $0,11045 \ldots$ \\
\hline 1,20 & 630 & 7 & 283,15 & 0,945 & 44 & 1,83 & 288,15 & $1,39900722 \ldots$ & 1890,1517 & 750,004155 & $6,3640150111187 \ldots$ & $0,11045 \ldots$ \\
\hline 1,35 & 630 & 7 & 283,15 & 0,945 & 44 & 1,83 & 288,15 & $1,39900722 \ldots$ & 1890,1517 & 750,004155 & $6,3640150111187 \ldots$ & $0,11045 \ldots$ \\
\hline 1,50 & 630 & 7 & 283,15 & 0,945 & 44 & 1,83 & 288,15 & $1,39900722 \ldots$ & 1890,1517 & 750,004155 & $6,3640150111187 \ldots$ & $0,11045 \ldots$ \\
\hline 1,65 & 630 & 7 & 283,15 & 0,945 & 44 & 1,83 & 288,15 & $1,39900722 \ldots$ & 1890,1517 & 750,004155 & $6,3640150111187 \ldots$ & $0,11045$. \\
\hline 1,80 & 630 & 7 & 283,15 & 0,945 & 44 & 1,83 & 288,15 & $1,39900722 \ldots$ & 1890,1517 & 750,004155 & $6,3640150111187 \ldots$ & $0,11045 \ldots$ \\
\hline 1,95 & 630 & 7 & 283,15 & 0,945 & 44 & 1,83 & 288,15 & 1,39900722 & 1890,1517 & 750,004155 & $6,3640150111187 \ldots$ & $0,11045 \ldots$ \\
\hline 2,10 & 630 & 7 & 283,15 & 0,945 & 44 & 1,83 & 288,15 & 1,39900722 & 1890,1517 & 750,004155 & $6,3640150111187 \ldots$ & $0,11045 \ldots$ \\
\hline 2,25 & 630 & 7 & 283,15 & 0,945 & 44 & 1,83 & 288,15 & $1,39900722 \ldots$ & 1890,1517 & 750,004155 & $6,3640150111187 \ldots$ & $0,11045 \ldots$ \\
\hline 2,40 & 630 & 7 & 283,15 & 0,945 & 44 & 1,83 & 288,15 & 1,39900722 & 1890,1517 & 750,004155 & $6,3640150111187 \ldots$ & $0,11045$. \\
\hline 2,55 & 630 & 7 & 283,15 & 0,945 & 44 & 1,83 & 288,15 & $1,39900722 \ldots$ & 1890,1517 & 750,004155 & $6,3640150111187 \ldots$ & $0,11045 \ldots$ \\
\hline 2,70 & 630 & 7 & 283,15 & 0,945 & 44 & 1,83 & 288,15 & 1,39900722 & 1890,1517 & 750,004155 & $6,3640150111187 \ldots$ & $0,11045 \ldots$ \\
\hline 2,85 & 630 & 7 & 283,15 & 0,945 & 44 & 1,83 & 288,15 & $1,39900722 \ldots$ & 1890,1517 & 750,004155 & $6,3640150111187 \ldots$ & $0,11045 \ldots$ \\
\hline 3,00 & 630 & 7 & 283,15 & 0,945 & 44 & 1,83 & 288,15 & $1,39900722 \ldots$ & 1890,1517 & 750,004155 & 6,36401501111187... & $0,11045 \ldots$ \\
\hline 3,15 & 630 & 7 & 283,15 & 0,945 & 44 & 1,83 & 288,15 & $1,39900722 \ldots$ & 1890,1517 & 750,004155 & $6,3640150111187 \ldots$ & $0,11045 \ldots$ \\
\hline 3,30 & 630 & 7 & 283,15 & 0,945 & 44 & 1,83 & 288,15 & $1,39900722 \ldots$ & 1890,1517 & 750,004155 & $6,3640150111187 \ldots$ & $0,11045$. \\
\hline
\end{tabular}

Fig. 2. Form for output of calculation of oil product parameters along the pipeline axis. 


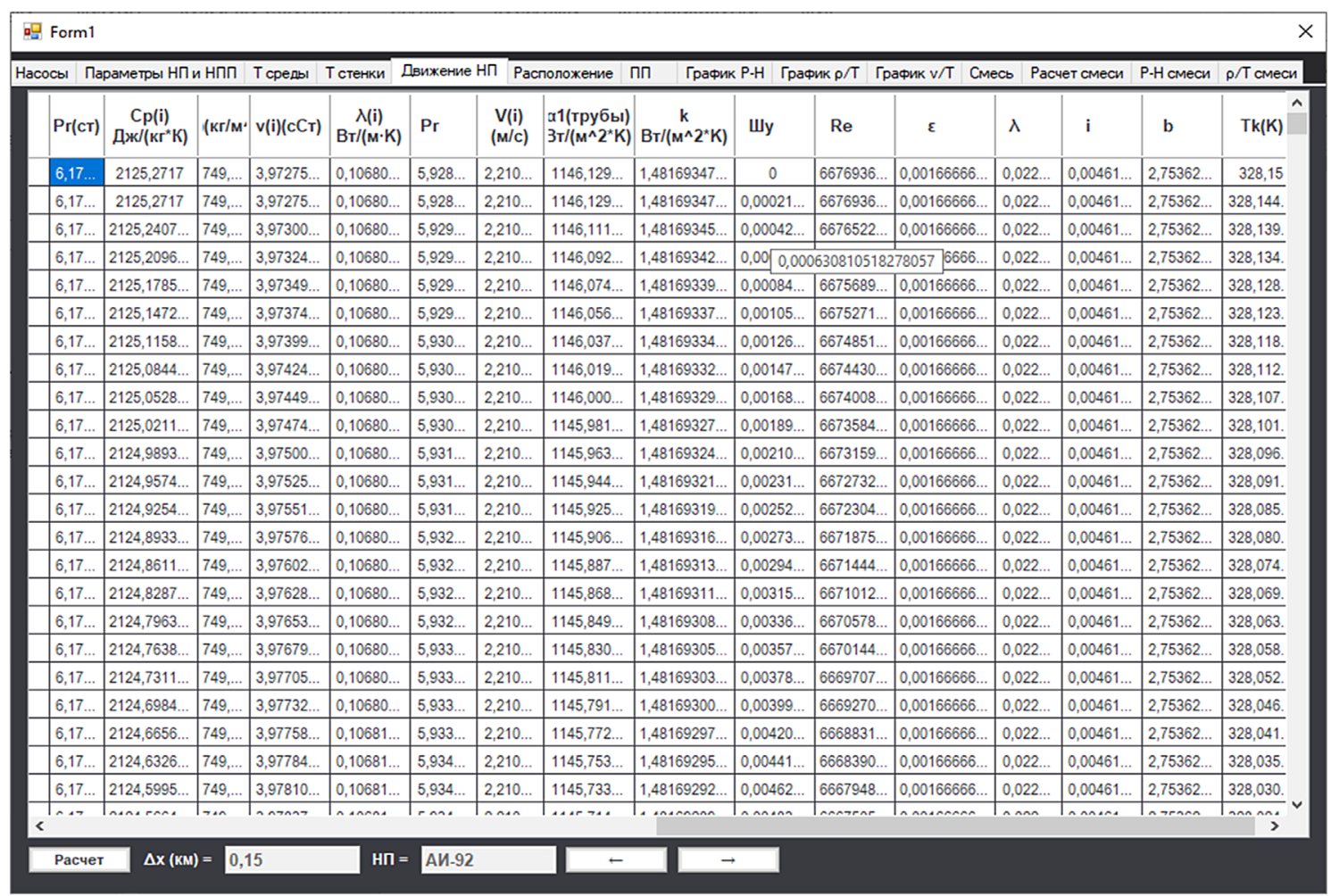

Fig. 3. Form for output of calculation of oil product parameters along the pipeline axis.

Table 4. The results of the studies under $Q=1044 \mathrm{~m}^{3} / \mathrm{h}$.

\begin{tabular}{|c|c|c|c|c|c|}
\hline$\emptyset 426 \times 7 \mathrm{~mm}$ & AI-95 + AI-92 & AI-92 + AI- 80 & $\mathrm{AI}-80+\mathrm{AI}-76$ & $\Delta \mathrm{H}$ & $\Delta \mathrm{P}$ \\
\hline Summer (South-North) & 69.676 & 68.745 & 68.114 & 600.395 & 4.136 \\
\hline Summer (North-South) & 70.477 & 69.523 & 68.877 & 603.908 & 4.162 \\
\hline Winter (Isothermal) & 83.865 & 82.539 & 81.638 & 664.242 & 4.581 \\
\hline Winter (South-North) & 84.192 & 82.857 & 81.950 & 665.611 & 4.591 \\
\hline Winter (North-South) & 85.615 & 84.243 & 83.311 & 671.356 & 4.634 \\
\hline
\end{tabular}

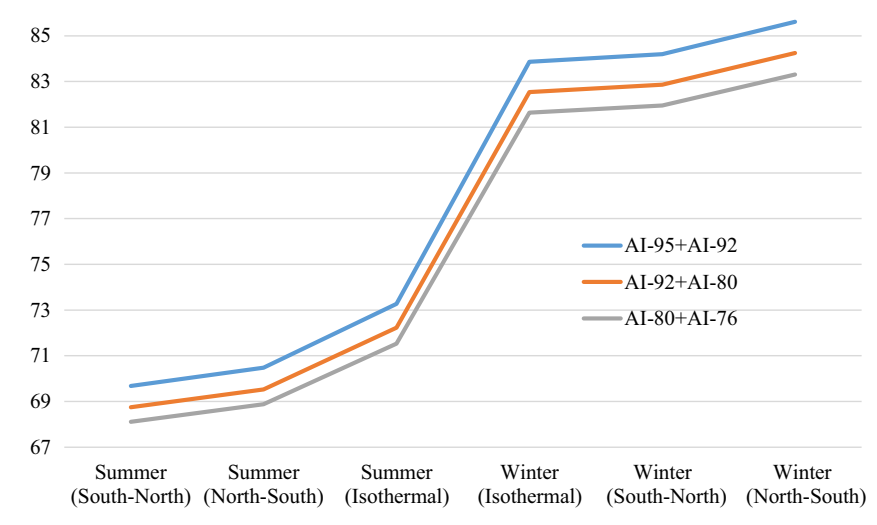

Fig. 4. Volume of the mixture formed under different pumping conditions.

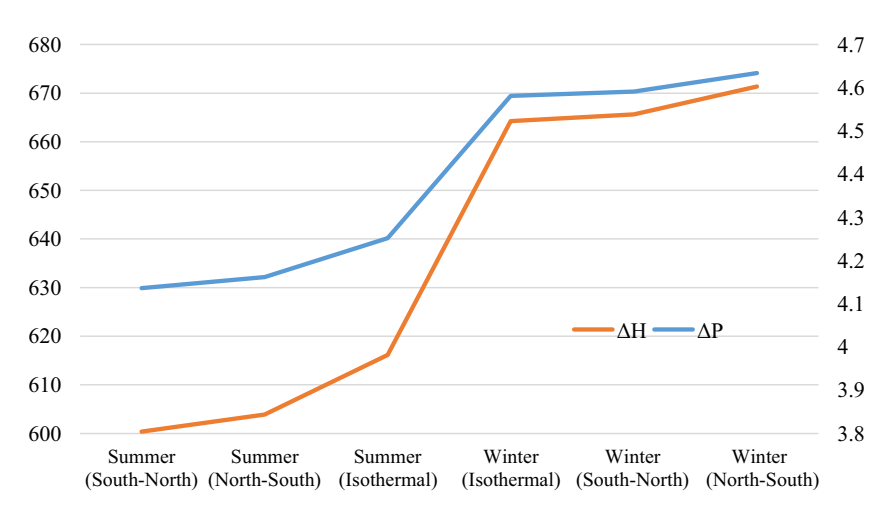

Fig. 5. Changing the pressure and head parameters at the ends of the linear section under different pumping conditions. 
Table 5. Research result where $Q=1800 \mathrm{~m}^{3} / \mathrm{h}$.

\begin{tabular}{lcccccc}
\hline & AI-95 + & AI-92 + & AI-80 + & & \\
$\emptyset 530 \times 7 \mathrm{~mm}$ & AI-92 & AI -80 & AI -76 & $\Delta \mathrm{H}$ & $\Delta \mathrm{P}$ \\
\hline Summer (South-North) & 87.234 & 86.108 & 85.345 & 538.440 & 3.671 \\
Summer (North-South) & 88.236 & 87.081 & 86.299 & 541.538 & 3.694 \\
Summer (Isothermal) & 91.599 & 90.345 & 89.494 & 551.908 & 3.770 \\
Winter (Isothermal) & 104.481 & 102.866 & 101.769 & 590.206 & 4.052 \\
Winter (South-North) & 104.844 & 103.219 & 102.115 & 591.276 & 4.060 \\
Winter (North-South) & 106.649 & 104.977 & 103.840 & 596.433 & 4.098 \\
\hline
\end{tabular}

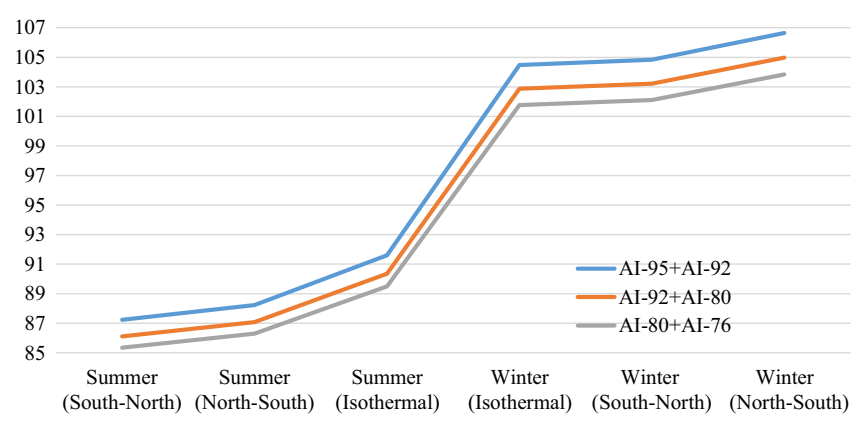

Fig. 6. Volume of the mixture formed under different pumping conditions.

of the dependence of the mixture volume on pumping conditions is shown in Figure 8, and the values of the required pressure drop and head are shown in Figure 9.

Based on the results of calculating the sequential pumping of four brands of automobile gasoline, it is worth noting the general and generally obvious trend for all grades that energy losses will increase with a decrease in temperature, which will lead to the need for more precise adjustment of pumping equipment at oil pumping stations.

As a result of the updated non-isothermal calculation for summer conditions, it should be noted that the required head for pumping in the specified modes is less than for the isothermal calculation for all grades, which may lead to an incorrect decision on regulating the pumping equipment and reducing the efficiency of the entire system. This is primarily due to the friction forces and temperature distribution along the length of the oil product pipeline. In winter, the opposite trend is observed, despite the forces of viscous friction, the head loss for pumping has become greater than for non-isothermal. This fact is due to the fact that for isothermal pumping, the average temperatures of the pumped product were taken in each of the periods. Failure to take into account thermal-hydraulic factors will lead to incorrect adjustment of the pumping equipment and the inability to provide the specified pipeline capacity, but increasing the accuracy of the model and, as a result, calculations will allow you to determine more accurately the energy loss at a given pumping mode and make the required adjustment.

One of the main results of modeling is the dependence of the volume of the resulting mixture on the viscosity of the

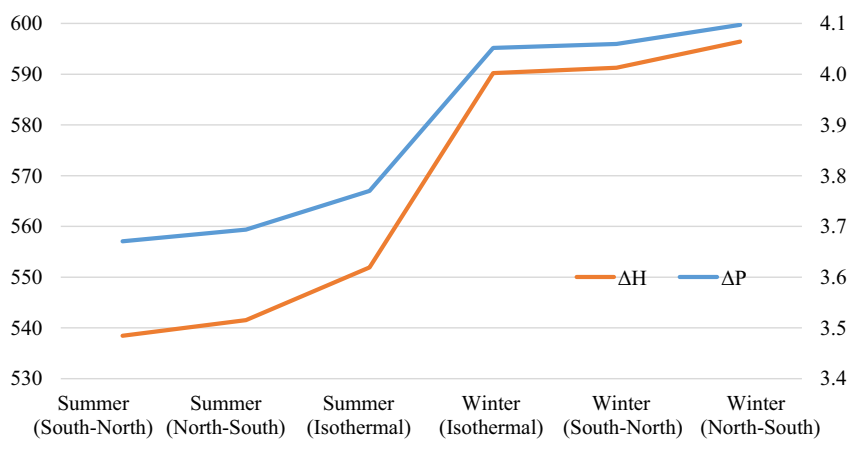

Fig. 7. Changing the pressure and head parameters at the ends of the linear section under different pumping conditions

contacting products, which is primarily due to the uneven displacement of the first product by the next product, and secondarily to the turbulent diffusion in the contact zone of two neighboring products.

As is known, the viscosity of petroleum products strongly depends on the temperature of the oil product under consideration, so it is important to take into account its effect on the mixture formation as accurately as possible. In the course of numerical modeling of mixture formation, the volume of the mixture was the smallest in summer when pumping from South to North, and the largest when pumping from North to South in winter. The calculated volume of the mixture during isothermal pumping for summer conditions turned out to be more than the specified one, and for winter time - less.

So, usually at the final point of the main oil product pipeline, the layout of the mixture of petroleum products is carried out by net, i.e. adding the mixture to the oil products that participated in the $[5,6,10]$. If the mixture is formed more than can be decomposed into individual oil products, then it must be separated again, but at the refinery [27, 29]. For this reason, the inaccuracy of modeling the mixture formation in winter will lead to the need to send part of the mixture for recycling, which will lead to additional problems and reduce the efficiency of the entire enterprise.

In the summer, the specified volume of the mixture has become smaller, and the head loss for pumping has also decreased, which will allow for more flexible regulation of pumping through the pipeline and, if necessary, slightly reduce the minimum possible volume of the batch of oil products and increase the pumping speed.

The simulation of petroleum products similar in their physical properties - automobile gasoline was performed above, but it is necessary to assess the impact of new factors taken into account when pumping several gasoline and Diesel Fuel (DF), for example, AI-95, AI-92, AI-80 and Diesel fuel. With sequential pumping of gasoline and diesel fuel, diesel fuel is located in a cycle between batches of the worst-quality gasoline $[5,6,17]$.

We will conduct a simulation of sequential pumping along the section of the oil product pipeline presented earlier, with the same parameters and flow rate, but we will replace AI-76 with DF, and in summer we will consider 
Table 6. Research result where $Q=2880 \mathrm{~m}^{3} / \mathrm{h}$.

\begin{tabular}{lccccc}
\hline & AI-95 + & AI-92 + & AI-80 + & & \\
$\emptyset 630 \times 7 \mathrm{~mm}$ & AI-92 & AI-80 & AI-76 & $\Delta \mathrm{H}$ & $\Delta \mathrm{P}$ \\
\hline Summer (South-North) & 103.017 & 101.746 & 100.885 & 529.875 & 3.621 \\
Summer (North-South) & 104.178 & 102.873 & 101.989 & 532.860 & 3.643 \\
Summer (Isothermal) & 107.968 & 106.548 & 105.586 & 542.559 & 3.715 \\
Winter (Isothermal) & 122.597 & 120.759 & 119.511 & 578.735 & 3.981 \\
Winter (South-North) & 122.979 & 121.130 & 119.874 & 579.669 & 3.988 \\
Winter (North-South) & 125.098 & 123.193 & 121.898 & 584.727 & 4.025 \\
\hline
\end{tabular}

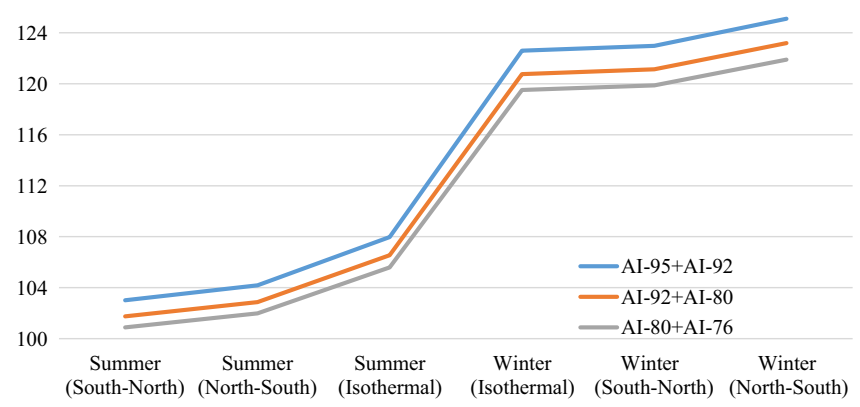

Fig. 8. Volume of the mixture formed under different pumping conditions.

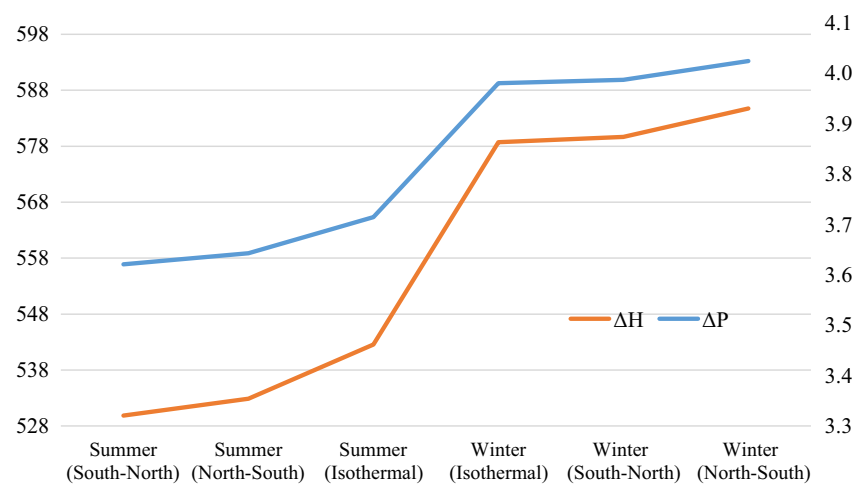

Fig. 9. Changing the pressure and head parameters at the ends of the linear section under different pumping conditions.

Summer Diesel Fuel (SDF), and in winter - Winter Diesel Fuel (WDF). Their main differences that are of interest to us are the different values of kinematic viscosity and density in SDF and WDF [36] (Tab. 3), as well as their application in different temperature conditions.

Numerical results of modeling pumping through a pipeline with a range of $\emptyset 426 \times 7 \mathrm{~mm}$ with a flow rate of $1044 \mathrm{~m}^{3} / \mathrm{h}$ are shown in Table 7 , a graphical representation of the dependence of the mixture volume on pumping conditions is shown in Figure 10, and the values of the required pressure drop and head are shown in Figure 11.

From the results obtained, it can be seen that during sequential pumping of various petroleum products by
Table 7. Research result where $Q=1044 \frac{\mathrm{m}^{3}}{\mathrm{~h}} v=2.175 \frac{\mathrm{m}}{\mathrm{s}}$ and pumping of gasoline and diesel fuel.

\begin{tabular}{lcccccc}
\hline & \multicolumn{5}{c}{ AI-80 +} \\
Diesel \\
$\emptyset 426 \times 7 \mathrm{~mm}$ & AI-95 + & AI-92 + & & \\
& AI-92 & AI-80 & winter) & $\Delta \mathrm{H}$ & $\Delta \mathrm{P}$ \\
\hline Summer (South-North) & 69.66 & 68.73 & 88.11 & 602.79 & 4.41 \\
Summer (North-South) & 70.49 & 69.53 & 91.34 & 608.27 & 4.45 \\
Summer (Isothermal) & 73.27 & 72.23 & 115.22 & 632.53 & 4.64 \\
Winter (Isothermal) & 83.86 & 82.54 & 137.48 & 684.35 & 5.01 \\
Winter (South-North) & 84.17 & 82.84 & 139.07 & 686.00 & 5.02 \\
Winter (North-South) & 85.64 & 84.27 & 146.83 & 695.62 & 5.09 \\
\hline
\end{tabular}

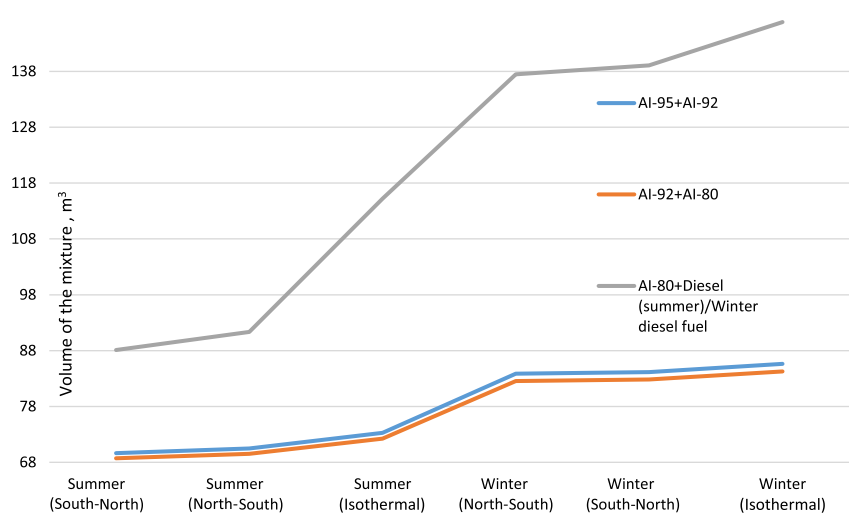

Fig. 10. Volume of the mixture formed under different pumping conditions.

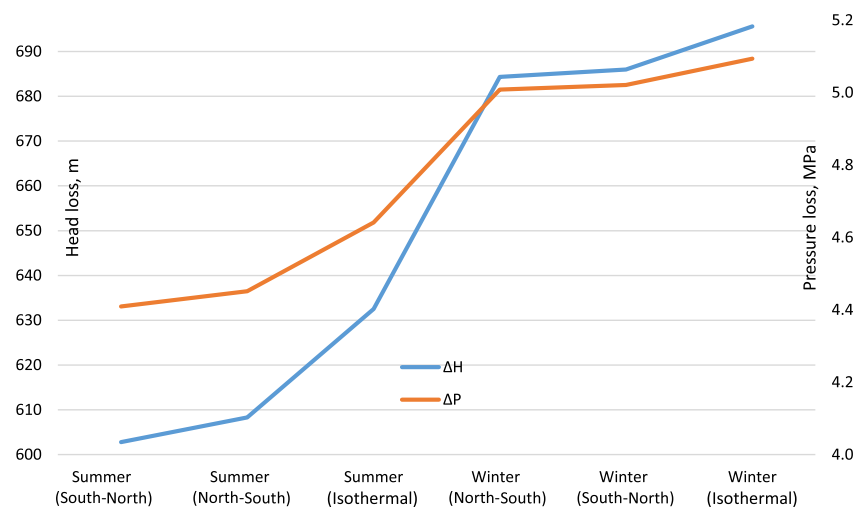

Fig. 11. Changing the pressure and head parameters at the ends of the linear section under different pumping conditions.

direct contact, the properties of which are quite different from each other, for example, automobile gasoline and diesel fuel, the volume of the mixture between gasoline (AI-92 + AI-80) for summer operating conditions was $68.73 \mathrm{~m}^{3}$ and $69.53 \mathrm{~m}^{3}$, depending on the direction of pumping, i.e. did not change. However, the volume of the mixture formed in the contact zone of automobile gasoline and diesel 
fuel (AI-80 + Diesel fuel) was significantly larger and amounted to $88.11 \mathrm{~m}^{3}$ and $91.34 \mathrm{~m}^{3}$ for summer operating conditions, depending on the pumping direction. This is due to the fact that diesel fuel is a more viscous petroleum product compared to automobile gasoline.

Consider the worst pumping conditions - in winter and the direction of pumping from North to South. Under these conditions, the volume of the mixture will increase in the contact zone of all petroleum products and for AI- $92+$ AI- 80 will be $84.27 \mathrm{~m}^{3}$, and the increase will be $22.6 \%$ of the most favorable conditions. This fact is associated with an increase in viscosity due to a decrease in the temperature of the pumped product and the environment. For AI- $80+$ winter diesel fuel, the volume of the mixture will be $146.83 \mathrm{~m}^{3}$, which corresponds to an increase of $74.24 \%$ when pumping in the summer period of operation in the direction from South to North. This is due to the fact that the viscosity of diesel fuel has a more pronounced dependence on temperature.

In addition, due to the participation in the sequential pumping of more viscous and dense oil products, the losses for pumping have sharply increased. this fact is most pronounced for winter pumping conditions and leads to the fact that the existing pumping equipment suitable for pumping in the summer time simply will not be able to pump over a given section. There are two ways out of this situation:

1. Necessary to install additional pumping equipment that will only be used in winter, which entails additional capital investments, but the increase in pressure at the outlet of the pumping station may not be able to withstand the pipeline itself, so it will be necessary to lay a safety margin by increasing the wall thickness or using other steel grades that are stronger and more expensive, which will also increase the overall cost of the project. This option may be relevant for the planned or projected oil product pipeline.

2. Necessary to reduce the volume flow rate on the section of the oil product pipeline. This option is relevant for already commissioned and operated oil product pipelines. In this case, there is no need to increase the outlet head and design the pipeline with a safety margin, but there are also disadvantages.

Consider the option of reducing the volume flow, the results of the modeling pipeline, range $\emptyset 426 \times 7 \mathrm{~mm}$ presented in Table 8, a graphical representation of the dependence of the volume of the mixture from pump - in Figure 12, and the values of the required differential pressure and head in Figure 13. The reduced flow rate in the considered variant was $900 \mathrm{~m}^{3} / \mathrm{h}$, which led to a reduction in losses from $695.62 \mathrm{~m}$ to $532.75 \mathrm{~m}$.

According to the results obtained, when the volume flow rate of pumping decreases, the volume of the mixture of transported products will increase. So for the contact zone AI-92+AI-80 under winter conditions, pumping will be $88.77 \mathrm{~m}^{3}$ (against $84.27 \mathrm{~m}^{3}$ before the reduction of pumping), which corresponds to an increase of $5.34 \%$. For AI-80+winter diesel fuel $-156.2 \mathrm{~m}^{3}$ (against $146.83 \mathrm{~m}^{3}$
Table 8. Research result where $Q=900 \frac{\mathrm{m}^{3}}{\mathrm{~h}} v=1.875 \frac{\mathrm{m}}{\mathrm{s}}$ and pumping of gasoline and diesel fuel.

\begin{tabular}{|c|c|c|c|c|c|}
\hline$\emptyset 426 \times 7 \mathrm{~mm}$ & $\begin{array}{c}\text { AI-95 }+ \\
\text { AI-92 }\end{array}$ & $\begin{array}{c}\text { AI-92 + } \\
\text { AI-80 }\end{array}$ & $\begin{array}{c}\text { AI-80 + } \\
\text { Diesel } \\
\text { (summer/ } \\
\text { winter) }\end{array}$ & $\Delta \mathrm{H}$ & $\Delta \mathrm{P}$ \\
\hline Summer (South-North) & 72.84 & 71.82 & 90.49 & 458.15 & 3.35 \\
\hline Summer (North-South) & 73.73 & 72.68 & 96.75 & 463.98 & 3.40 \\
\hline Summer (Isothermal) & 76.78 & 75.65 & 122.39 & 483.04 & 3.55 \\
\hline Winter (Isothermal) & 88.35 & 86.91 & 146.31 & 524.74 & 3.84 \\
\hline Winter (South-North) & 88.71 & 87.25 & 148.12 & 525.35 & 3.85 \\
\hline Winter (North-South) & 90.26 & 88.77 & 156.20 & 532.75 & 3.90 \\
\hline
\end{tabular}

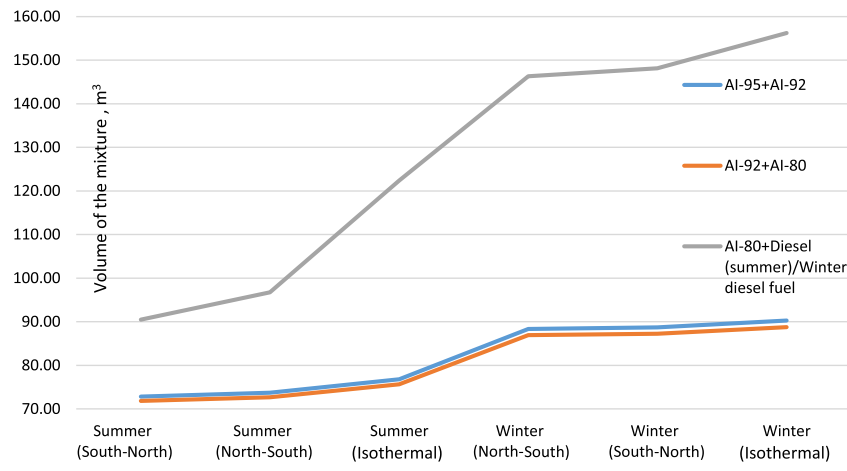

Fig. 12. Volume of the mixture formed under different pumping conditions.

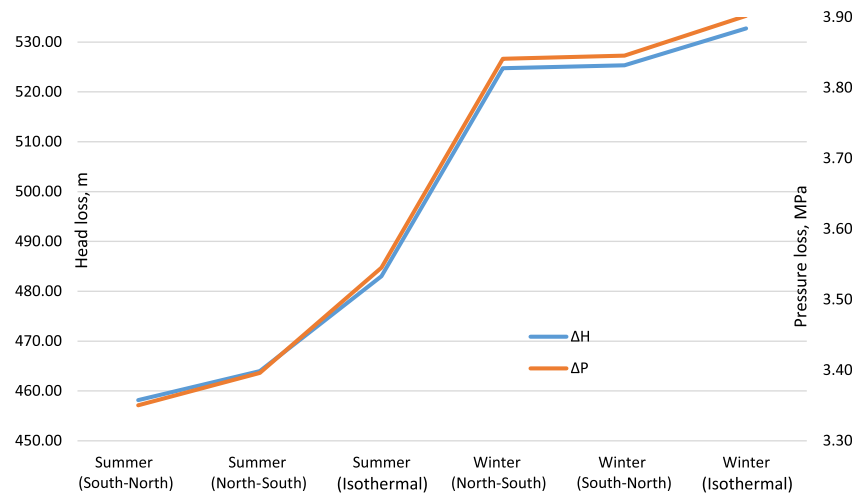

Fig. 13. Changing the pressure and head parameters at the ends of the linear section under different pumping conditions.

before the reduction of pumping), which corresponds to $6.38 \%$.

The formation of the mixture as a whole is a negative consequence of the sequential pumping of various petroleum products, not to mention its increase, which will require recalculation of the minimum possible batch volume for its layout at the final point, provided that there is a quality reserve for the transported fuels. 
Table 9. Research result where $Q=1800 \frac{\mathrm{m}^{3}}{\mathrm{~h}} \mathrm{v}=2.391 \frac{\mathrm{m}}{\mathrm{s}}$ and pumping of gasoline and diesel fuel.

\begin{tabular}{|c|c|c|c|c|c|}
\hline$\emptyset 530 \times 7 \mathrm{~mm}$ & $\begin{array}{c}\text { AI-95 }+ \\
\text { AI-92 }\end{array}$ & $\begin{array}{c}\mathrm{AI}-92+ \\
\mathrm{I}-80\end{array}$ & $\begin{array}{c}\text { AI-80 + } \\
\text { Diesel } \\
\text { (summer/ } \\
\text { winter) }\end{array}$ & $\Delta \mathrm{H}$ & $\Delta \mathrm{P}$ \\
\hline Summer (South-North) & 87.22 & 86.10 & 110.14 & 589.25 & 4.58 \\
\hline Summer (North-South) & 88.25 & 87.09 & 113.42 & 599.03 & 4.66 \\
\hline Summer (Isothermal) & 91.60 & 90.34 & 142.72 & 662.69 & 5.19 \\
\hline Winter (Isothermal) & 104.48 & 102.87 & 170.08 & 726.21 & 5.62 \\
\hline Winter (South-North) & 104.82 & 103.20 & 171.87 & 728.94 & 5.64 \\
\hline Winter (North-South) & 106.67 & 105.00 & 181.76 & 749.64 & 5.81 \\
\hline
\end{tabular}

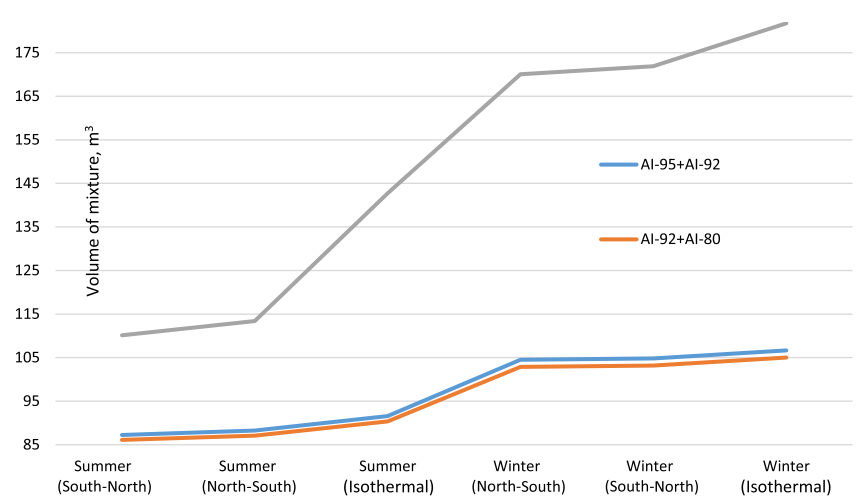

Fig. 14. Volume of the mixture formed under different pumping conditions.

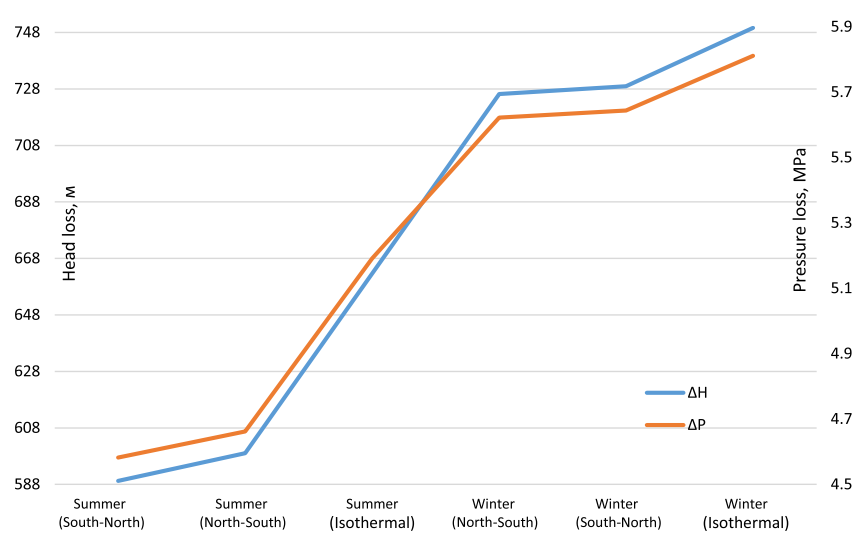

Fig. 15. Changing the pressure and head parameters at the ends of the linear section under different pumping conditions.

In the following, numerical results of modeling the operation of a section of the main oil product pipeline for sequential pumping for grades $\emptyset 530 \times 7 \mathrm{~mm}$ and $\emptyset 630 \times 7 \mathrm{~mm}$ at the initial flow rate are presented in Tables 9 and 11, respectively, and a graphical representation in Figures 14, 15 and 18, 19, respectively. Also these modeling options
Table 10. Research result where $Q=1620 \frac{\mathrm{m}^{3}}{\mathrm{~h}}$ $v=2.192 \frac{\mathrm{m}}{\mathrm{s}}$ and pumping of gasoline and diesel fuel.

\begin{tabular}{lccccc}
\hline & \multicolumn{5}{c}{$\begin{array}{c}\text { AI-80 }+ \\
\text { Diesel } \\
\text { (summer/ }\end{array}$} \\
$\emptyset 530 \times 7 \mathrm{~mm}$ & AI-95 + & AI-92 + & \\
\hline Summer (South-North) & 89.91 & 88.71 & 113.43 & 486.75 & 3.79 \\
Summer (North-South) & 91.00 & 89.76 & 118.09 & 495.69 & 3.86 \\
Summer (Isothermal) & 94.59 & 93.25 & 148.90 & 548.82 & 4.30 \\
Winter (Isothermal) & 108.31 & 106.60 & 177.70 & 602.10 & 4.66 \\
Winter (South-North) & 108.69 & 106.96 & 179.66 & 604.43 & 4.68 \\
Winter (North-South) & 110.63 & 108.85 & 189.89 & 621.59 & 4.82 \\
\hline
\end{tabular}

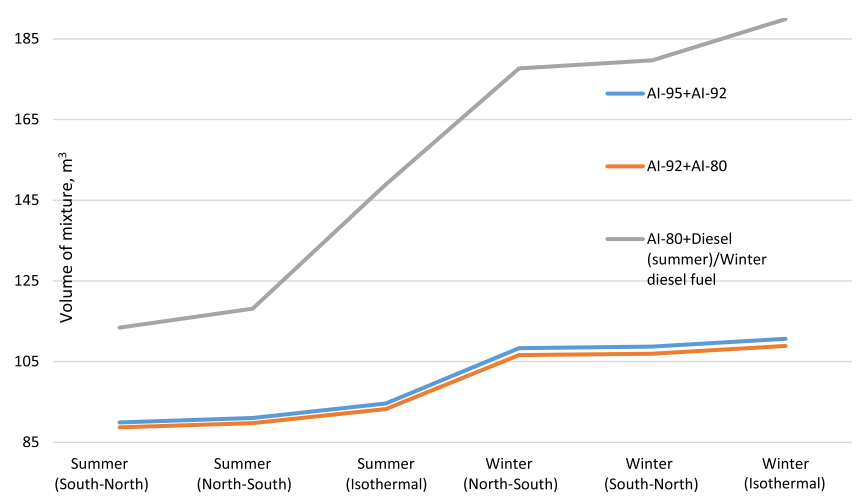

Fig. 16. Volume of the mixture formed under different pumping conditions.

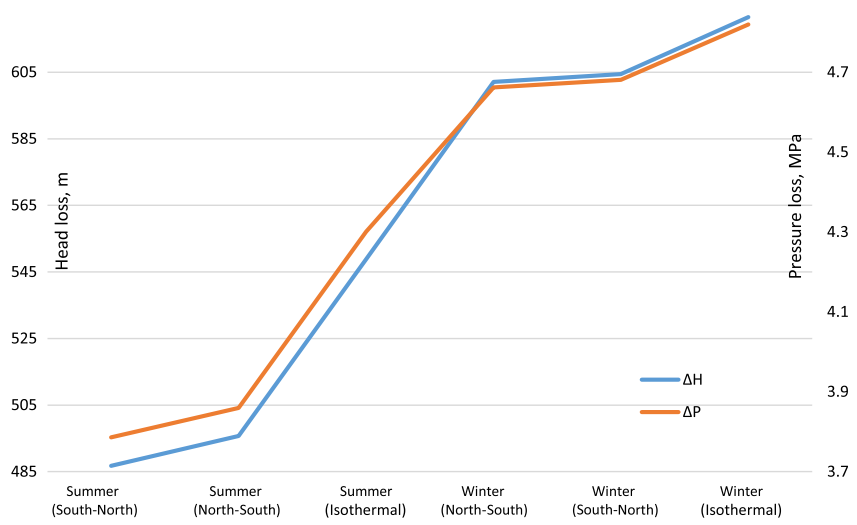

Fig. 17. Changing the pressure and head parameters at the ends of the linear section under different pumping conditions.

are characterized by an increase in losses when the AI-76 is replaced by diesel fuel, in summer - by summer, in winter by winter.

Therefore, for assortments $\emptyset 530 \times 7 \mathrm{~mm}$ and $\emptyset 630 \times$ $7 \mathrm{~mm}$ also been carried out by lowering the volumetric flow of $1800 \mathrm{~m}^{3} / \mathrm{h}$ to $1620 \mathrm{~m}^{3} / \mathrm{h}$, and $2880 \mathrm{~m}^{3} / \mathrm{h}$ to $2520 \mathrm{~m}^{3} / \mathrm{h}$, 
Table 11. Research result where $Q=2880 \frac{\mathrm{m}^{3}}{\mathrm{~h}}$ $v=2.684 \frac{\mathrm{m}}{\mathrm{s}}$ and pumping of gasoline and diesel fuel.

\begin{tabular}{|c|c|c|c|c|c|}
\hline$\emptyset 630 \times 7 \mathrm{~mm}$ & $\begin{array}{c}\text { AI-95 + } \\
\text { AI-92 }\end{array}$ & $\begin{array}{c}\text { AI-92 + } \\
\text { AI-80 }\end{array}$ & $\begin{array}{c}\text { AI-80 + } \\
\text { Diesel } \\
\text { (summer/ } \\
\text { winter) }\end{array}$ & $\Delta \mathrm{H}$ & $\Delta \mathrm{P}$ \\
\hline Summer (South-North) & 103.01 & 101.73 & 129.06 & 607.27 & 4.85 \\
\hline Summer (North-South) & 104.19 & 102.88 & 133.98 & 617.59 & 4.94 \\
\hline Summer (Isothermal) & 107.97 & 106.55 & 166.20 & 701.92 & 5.64 \\
\hline Winter (Isothermal) & 122.60 & 120.76 & 197.72 & 775.75 & 6.14 \\
\hline Winter (South-North) & 122.96 & 121.11 & 199.65 & 776.63 & 6.15 \\
\hline Winter (North-South) & 125.12 & 123.21 & 211.39 & 802.97 & 6.36 \\
\hline
\end{tabular}

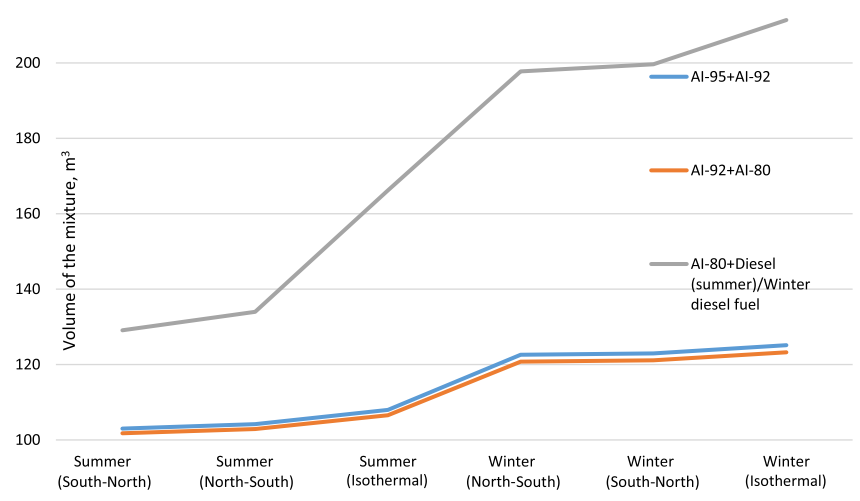

Fig. 18. Volume of the mixture formed under different pumping conditions.

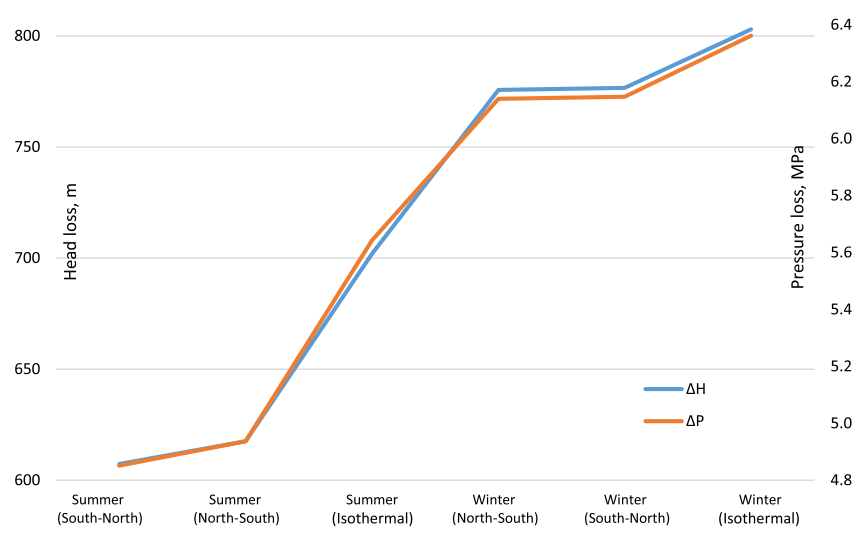

Fig. 19. Changing the pressure and head parameters at the ends of the linear section under different pumping conditions.

the results of which are presented not only for winter but for the summer mode of operation in Tables 10 and 12, respectively, and in Figures 16, 17 and 20, 21 respectively. As a result, for the other two grades, a decrease in the
Table 12. Research result where $Q=2520 \frac{\mathrm{m}^{3}}{\mathrm{~h}}$ $v=2.246 \frac{\mathrm{m}}{\mathrm{s}}$ and pumping of gasoline and diesel fuel.

\begin{tabular}{|c|c|c|c|c|c|}
\hline$\emptyset 630 \times 7 \mathrm{~mm}$ & $\begin{array}{c}\text { AI-95 }+ \\
\text { AI-92 }\end{array}$ & $\begin{array}{c}\mathrm{AI}-92+ \\
\mathrm{AI}-80\end{array}$ & $\begin{array}{c}\text { AI-80 + } \\
\text { Diesel } \\
\text { (summer/ } \\
\text { winter) }\end{array}$ & $\Delta \mathrm{H}$ & $\Delta \mathrm{P}$ \\
\hline Summer (South-North) & 106.89 & 105.51 & 135.09 & 477.03 & 3.8 \\
\hline Summer (North-South) & 108.17 & 106.75 & 139.30 & 486.65 & 3.8 \\
\hline Summer (Isothermal) & 112.30 & 110.75 & 175.29 & 553.60 & 4.4 \\
\hline Winter (Isothermal) & 128.18 & 126.19 & 208.94 & 610.41 & 4.8 \\
\hline & 128.59 & 126.59 & 211.08 & 613.23 & 4.8 \\
\hline Winter (North-South) & 130.89 & 128.83 & 223.37 & 633.96 & 5.0 \\
\hline
\end{tabular}

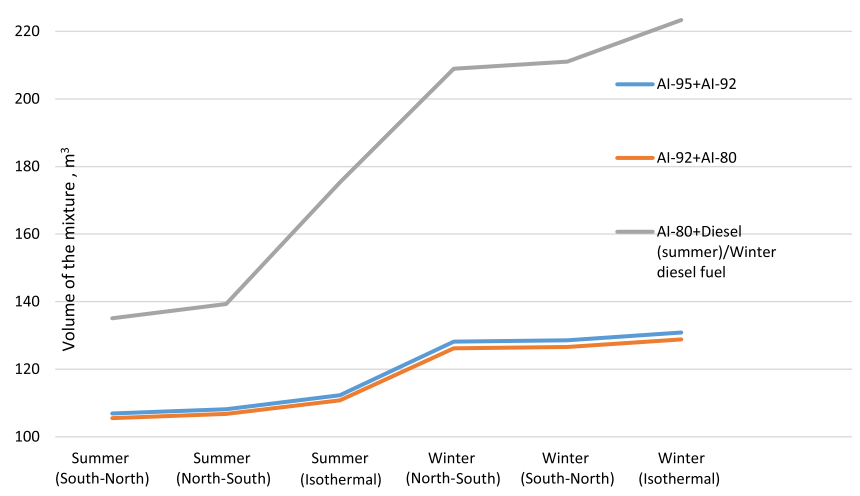

Fig. 20. Volume of the mixture formed under different pumping conditions.

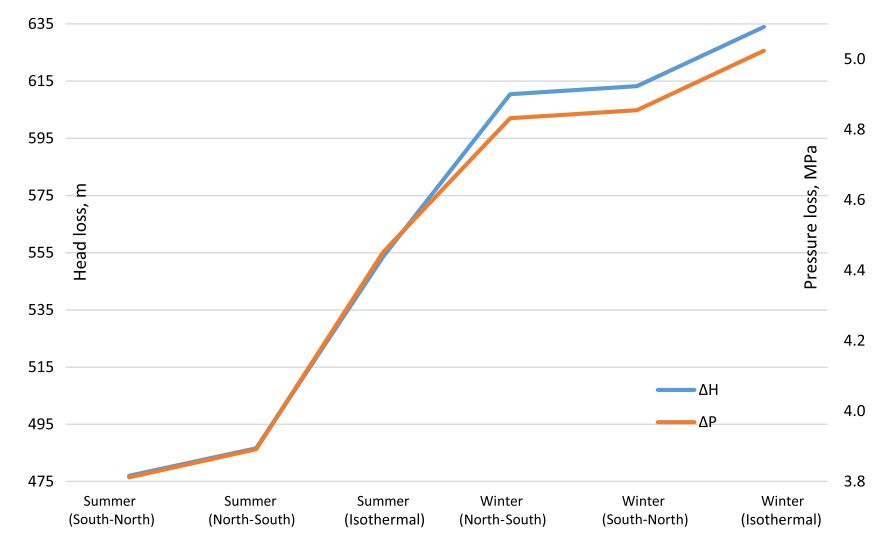

Fig. 21. Changing the pressure and head parameters at the ends of the linear section under different pumping conditions.

volume flow rate of pumping also led to an increase in the volume of the mixture formed during pumping. Changes in the volume of the mixture at a reduced mode are shown in Table 13. 
Table 13. Change in the volume of the mixture when the pumping mode is lowered.

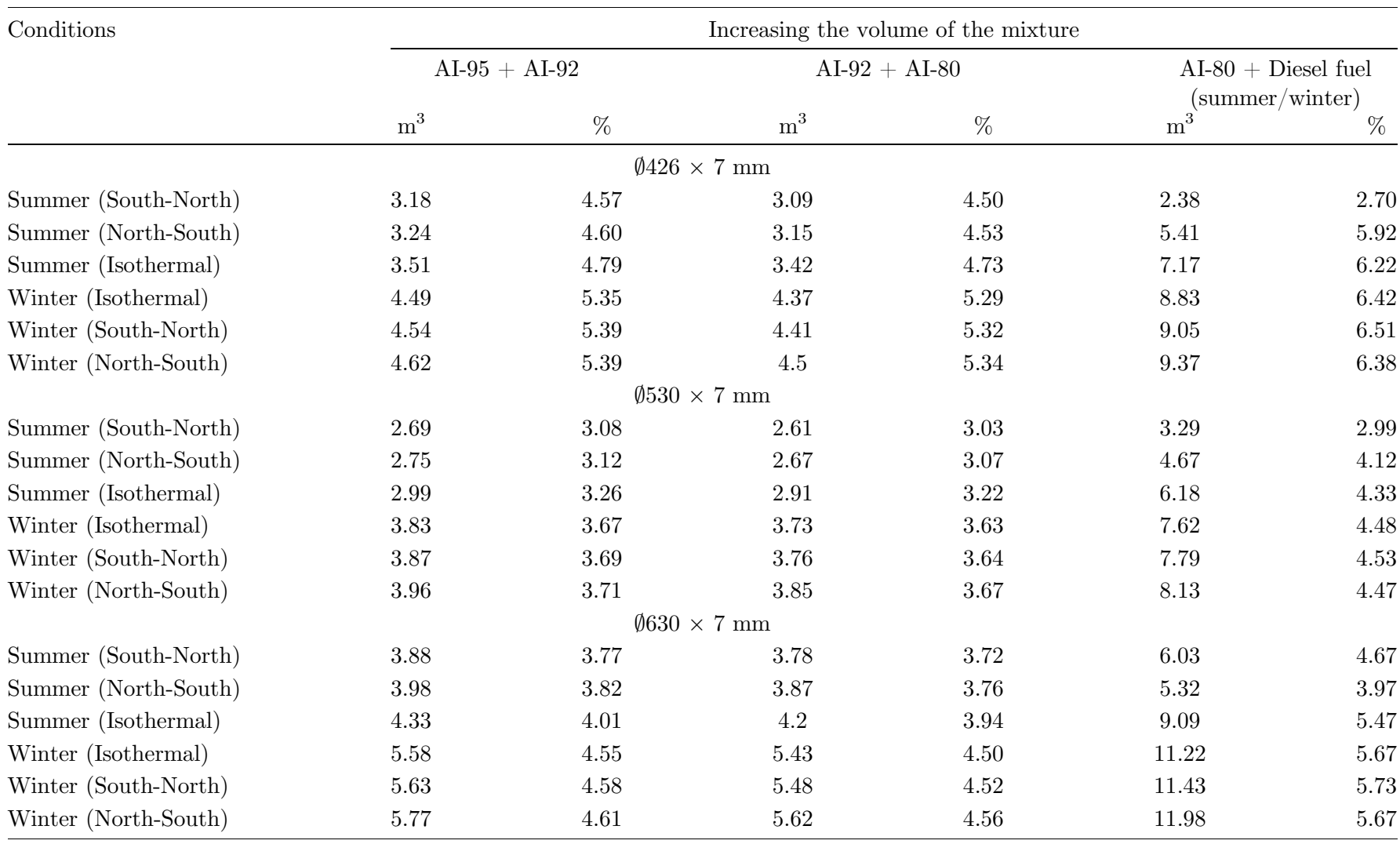

\section{Conclusion}

Despite the fact that sequential pumping of petroleum products of various brands by direct contact is one of the most cost-effective modes of transport for large volumes of transportation, this method has a number of disadvantages, so taking into account any additional factors is important, which showed:

1. the volume of the mixture when pumping in the North-South direction is greater than in the SouthNorth direction;

2. when pumping in winter, the volume of the mixture increases;

3 . in the implementation of pumping in the winter there is an increase of head losses and pressure;

4. when pumping heavier fuels, the properties of which are more dependent on temperature, there are large fluctuations throughout the year in the values of the mixture volumes, pressure losses and head losses on the section of the oil product pipeline.

Taking into account the change in the temperature distribution of the soil surrounding the pipeline along its route makes it possible to more accurately calculate the volume of the resulting mixture of oil products. This allows you to accurately estimate the required volume of the batch required for the implementation for the complete layout of the mixture for the transported oil products in the presence of their quality stock [10].

Based on the strong fluctuations during the year in the values of head losses and pressure losses, it was proved that it is necessary to regulate pumping equipment or pumping flow rate when transporting heavier fuels with sequential pumping for the implementation of the pumping process itself.

The proposed algorithm makes it possible to establish the possibility of tracking the process of transportation of oil products during sequential and non-isothermal pumping by direct contact in real time, taking into account parametric factors.

\section{References}

1 Deineko S.V., Alikhashkin A.S., Shestakov R.A., Ulanov V.V. (2018) Main technological equipment and processes for oil and petroleum products transportation, National University of Oil and Gas «Gubkin University», Moscow, Russia.

2 Kitaev S.V. (2018) Technical diagnostics of oil and oil products pipeline transport facilities, Ufa State Petroleum Technological University, Ufa, Russia. 
3 Vasilkovsky V.V. (1991) Development of energy-saving technology for sequential pumping through branched oil product pipelines, PhD Thesis, National University of Oil and Gas «Gubkin University», Moscow.

4 Sunagatullin R, Timofeev F, Kuznetsov A, Oludina Y (2019) Relevant issues on quality evaluation of petroleum pipeline preparation for oil product transportation, Oil \& Gas Science and Technology - Rev. IFP Energies nouvelles 74, 44. https://doi.org/10.2516/ogst/2018098.

5 Lurie M.V., Mastobayev B.N., Revel-Muroz P.A., Sosenko A.E. (2019) Design and operation of oil pipelines, National University of Oil and Gas «Gubkin University», Moscow, Russia.

6 Korolenok A.M., Lurie M.V., Timofeev F.V. (2012) Expansion of the range of light oil products transported through pipelines using the sequential method, Science and Technology of Pipeline Transportation of Oil and Petroleum Products 8, 4, 40-43.

7 Zorya E.I., Korolenok A.M., Losenkova O.V., Yu N.K. (2018) Fundamentals of resource conservation in the turnover of hydrocarbons, Max Press, Moscow, Russia.

8 Magomedov I.R. (2019) Problems of terminology in customs control of oil and petroleum products, Economics 180, 11, $65-70$.

9 Stigneev I.V. (2017) Analysis of Russian oil and oil products exports under sanctions, Customs and foreign economic activity of companies 3, 2, 1-8.

10 Lurie M.V., Timofeev F.V., Sereda S.V. (2017) Mix layout for sequential pumping of petroleum products, Science and Technology of Pipeline Transportation of Oil and Petroleum Products 7, 2, 42-47.

11 Yablonsky V.S., Yufin V.A., Budarov I.P. (1959) Sequential pumping of petroleum products and oils through main pipelines, Gostoptekhizdat, Moscow, Russian.

12 Lurie M.V. (1979) Optimization of sequential pumping of petroleum products, Nedra, Moscow, Russia.

13 Nechval M.V., Novoselov V.F., Tugunov P.I. (1976) Sequential pumping of oil and oil products through main pipelines, Nedra, Moscow, Russia.

14 Polyakov V.A., Shestakov R.A. (2018) Systematic approach to pipeline design, National University of Oil and Gas «Gubkin University», Moscow, Russia.

15 Didkovskaya A.S., Lurie M.V. (2016) Iterative algorithm for hydraulic calculation of non-isothermal oil pumping, Science and Technology of Pipeline Transportation of Oil and Petroleum Product 2, 50-55.

16 Lurie M.V. (2014) Algorithm for calculating quasi-steadystate modes of non-isothermal oil pumping, Science and Technology of Pipeline Transportation of Oil and Petroleum Product 2, 128-131.

17 Lurie M.V. (2012) Mathematical modeling of pipeline transportation of oil, oil products and gas, National University of Oil and Gas «Gubkin University», Moscow, Russia.

18 Gong J., Wang Q., Wang W., Guo Y. (2010) The calculation method of mixing volume in a products pipeline, in: 8th International Pipeline Conference, Calgary, Canada, Vol. 3, pp. 393-398.

19 Dombalov D.U., Melnikov D.I., Drozdov D.A. (2016) Determination of the effective diffusion coefficient and volume of the mixture during sequential pumping of fuel of various groups and grades by direct contact on collapsible pipelines, Science and Technology of Pipeline Transportation of Oil and Petroleum Product 6, 1, 30-38.
20 Shestakov R.A. (2020) Research of distribution of oil flow in the pipeline with looping, J. Phys. Conf. Series 1679, 052035. https://doi.org/10.1088/1742-6596/1679/5/052035.

21 Golunov N.N. (2018) Parameters of sequential pumping of petroleum products using small anti-turbulence additives to reduce the volume of the resulting mixture, Territory of Neftegaz 13, 5, 68-72.

22 Mayorov N.S., Istomova M.A. (2020) Sequential pipeline pumping of petroleum products, Business Magazine Neftegaz. $R U$ 99.5, 3.5, 45-50.

23 Sereda S.V., Lyapin A.Y., Dubovoy E.S., Timofeev F.V., Vishnevskaya Yu.A. (2020) Analysis of the possibility of using the method of infrared spectroscopy to determine the boundaries of the zone of mixing of petroleum products, Science and Technology of Pipeline Transportation of Oil and Petroleum Product 10, 1, 64-69.

24 Li Y., Chen M., Qiang X. (2020) Simultaneous scheduling of multi-product pipeline distribution and depot inventory management for petroleum refineries, Chem. Eng. Sci. 220, 115618.

25 Dimas D., Murata V.V., Neiro S.M.S., Relvas S., BarbosaPóvoa A.P. (2018) Multiproduct pipeline scheduling integrating for inbound and outbound inventory management, Comput. Chem. Eng. 115, 377-396.

26 Zhang H., Liang Y., Liao Q., Shen Y., Yan X. (2018) A selflearning approach for optimal detailed scheduling of multiproduct pipeline, J. Comput. Appl. Math. 327, 41-63.

27 Kirschstein T. (2018) Planning of multi-product pipelines by economic lot scheduling models, Eur. J. Oper. Res. 264, 327-339.

28 Zhou X., Zhang H., Xin S., Yan Y., Long Y., Yuan M., Liang Y. (2020) Future scenario of China's downstream oil supply chain: Low carbonoriented optimization for the design of planned multi-product pipelines, J. Clean. Prod. 244, 118866.

29 Chen H., Zuo L., Changchun W., Li Q. (2019) An MILP formulation for optimizing detailed schedules of a multiproduct pipeline network, Transp. Res. Part E 123, 142-164.

30 Mostafaei H., Castro P.M., Ghaffari-Hadigheh A. (2015) A novel monolithic MILP framework for lot-sizing and scheduling of multiproduct treelike pipeline networks, Indus. Eng. Chem. Res. 54, 37, 9202-9221.

31 Zhapbasbayev U.K., Makhmotov E.S., Bekibayev T.T., Ramazanova G.I., Rziyev S.A. (2015) Calculation of the optimal pumping temperature for oil transportation, Science and Technology of Pipeline Transportation of Oil and Petroleum Product 5, 4, 61-65.

32 Didkovskaya A.S., Lurie M.V. (2015) Universal algorithm for numerical calculations of stationary modes of oil pipelines operation, Science and Technology of Pipeline Transportation of Oil and Petroleum Product 5, 4, 86-91.

33 Zhapbasbaev U.K., Makhmotov E.S., Ramazanova G.I., Bekibaev T.T. (2018) Calculations of energy-saving modes of sequential pumping of oil mixtures on the section of the main oil pipeline, Science and Technology of Pipeline Transportation of Oil and Petroleum Product 8, 3, 30-38.

34 Vanchugov I.M. (2019) Computer simulation of mixing processes during sequential pumping of oil and petroleum products, in: 73rd International Youth Scientific Conference «Oil and Gas-2019», National University of Oil and Gas «Gubkin University», Moscow, Russia, pp. 106-107.

35 GOST 32513-2013 Motor Fuels. Unleaded petrol. Technical conditions.

36 GOST 305-2013 Diesel Fuel. Technical conditions. 